\title{
Where Do We Go Now? Adult and Workforce Education Policy Post-2020
}

\author{
Elizabeth A. Roumell, Texas A\&M University
}

In this essay, I argue that our recent pivot toward digital learning, in addition to the social discontent and economic turbulence exacerbated by the pandemic, requires a re-imagining of how we "do" adult and workforce education (AWE) policy. First, I briefly describe the 2014 Workforce Innovation and Opportunities Act (WIOA) policy. Next, I present findings from recent research on AWE policy development and identify substantial policy gaps. I emphasize a pressing need to return to the proverbial policy drawing board in AWE policy and invite our field to imagine a future for AWE that promotes a socially conscientious, inclusive, and democratic society and responds to the very real demand for workforce development reform, and the urgency of reducing earnings inequality.

\section{Current Policy}

Recent legislative efforts (WIOA) have worked toward integrating a wide variety of systems and to improve interoperability of adult educational, workforce, and social programming, and reduce the duplication of services. The primary aim was to economize and streamline educational opportunities for adults, and ultimately to help them maximize their earning potential (Brown \& Holcomb, 2018; McDonnell \& Soricone, 2018; Mortrude, 2018). In addition to improving cooperation and coordination between complimentary services, WIOA also further required providers to enhance wraparound services addressing various barriers many adults must overcome in order to participate in educational opportunities (Patterson, 2018; Prins \& Clymer, 2018). Another legislative aim was to create common understandings and measures to improve comparability of learning outcomes and measures for the purpose of accountability and research (Alamprese, 2016).

Efforts spurred by the Career Pathways (U.S. Department of Labor, 2012, 2016) initiative intended to bring academic improvement together with workplace training by aligning adult education, community college, human services, and workforce development efforts (Mortrude, 2018). Career Pathways initiatives are interposed between WIOA, the Higher Education Act, and the Strengthening Career \& Technical Education for the $21^{\text {st }}$ Century Act (Perkins V) federal legislation. Career Pathways was primarily focused on the transition into postsecondary education and vocational, career, and technical training, and aimed to make educational trajectories clearer for adult learners and reduce the amount of time needed to obtain measurable learning gains, qualifications, and ultimately employment (Campbell et al., 2016; Uvin, 2018). 
From a learning outcomes and economic standpoint, the aims of both Career Pathways and WIOA are reasonable and the legislation presents an inexorable argument for tightening links between education and labor markets. However, over the decades, many have criticized the employment-driven AWE policy framing that primarily conceives of adult learning as a means to an economic end (Finnegan, 2016; Milana \& McBain, 2015; Rose, 1999; Sandlin, 2005). Eyster and Nightingale (2017) explain that while little new funding at the federal level was authorized through WIOA, the aim of the legislation was to "shift the available funding through WIOA and the largest discretionary grant programs administered by the Department of Labor more toward developing training programs for in-demand jobs" (p. 5). Many reports suggest that training programs embedded within an employment context are, indeed, more effective (U.S. Department of Labor, 2014; Schochet et al., 2008), and that adults who receive specialized academic and career coaching and targeted support services tend to see better outcomes overall (Anderson et al., 2016; McConnell et al., 2016). Due to limited funding, however, only a very small percentage of U.S. workers are actually served.

Concerns have been expressed that the focus on measurable learning gains and employment, in addition the performance measures required of providers, may unwittingly push providers to prioritize learners who are better able to "make the grade." It has been argued that this focus could further disadvantage marginalized adult learners, especially adults who need the most literacy skills development, and/or those whose primary goal is not attaining employment (Ladinsky, 2017; Pickard, 2016, 2019). It has also been argued that this narrowing in focus and procedural formalization may render community providers less flexible in their ability to meet the needs of adult learners locally (Jacobson, 2017).

The array of competing commitments providers face adds to organizational constraints and may ultimately limit AWE access and reach (Alfred, 2020). AWE providers must attend to cumulating state and federal regulations in addition to their long list of daily functions, continually seek ways to supplement miniscule and soft budgets, and manage the challenges of retaining instructors and volunteers. Additionally, the climate of scarcity and limited funding has not only increased competition between educational sectors and providers for adult learners (Bok, 2013), but also pitted different models of adult education against one another for resources (Rasmussen, in press). Many also question how the varieties of functions of adult education can meaningfully be integrated under the broader workforce development rubric, if the emphasis and measures are centrally homed in on employment (Belzer \& Pickard, 2015; Belzer, 2017). McHugh and Doxsee argue, for example, that "Without adult education that is not bound to employment-focused outcome measures, it is extremely difficult to meet the needs of immigrants and refugees seeking to integrate into the social fabric of their communities, support their children's educational success, and ultimately become naturalized citizens" (2018, p. 2).

These critiques are warranted. What is missing, however, is the identification of specific areas of policy weakness that we can use to generate suggestions for alternative AWE models and approaches. In some recent policy analysis research, I directly examined the AWE legislative documents (Roumell et al., 2019, 2020) which helped reveal areas where policy is underdeveloped. With this kind of practical information in hand, we may be better able to identify solutions and activate stakeholders to take action and make improvements. 


\section{Holes in the Policy}

U.S. federal AWE policy development occurs in a pattern of "waves" of policy reform in response to major historical, economic, and social events. Such patterns in policy development illustrate that AWE policy tends to be reactionary, and that initiatives or amendments have been tacked onto longstanding legislation (e.g., Wagner Peyser Act, 1933). With WIOA, the beginning of a new policy wave and possible substantive overhaul of AWE policy is discernable. Recently amplified social and economic challenges may also suggest a favorable opportunity structure for further policy reform.

The systematic coding of legislative documents revealed policy areas in need of further development. Ongoing concern about insufficient funding notwithstanding, the analyses provide evidence to support the assertion that AWE policy needs further attention in these areas:

- Educational technologies; learning, administrative, and productivity applications; and infrastructure to support digital literacy in adult learning;

- Transformation of teaching and learning practice through professional development; improvement of instructional systems and programming, and other sources of support for teaching and learning practices;

- Integration, cooperation, and responsiveness of policy coordinating between varying educational sectors; and

- Equity and inclusion: recognition and systems responses to social issues and matters of diversity, inclusion, and equity in educational programming specifically, and society more broadly, and improved support for workforce development to address earnings inequality.
AWE policy resides at the crossroads of where economic and social policy meet. The legislative language and intent show how federal AWE policy aims to use education and job training as vehicles for addressing broader systemic social and economic issues. The promotion of public and accessible adult learning opportunities is a strategy for engendering both individual and wider social and economic improvement. Economic empowerment is an essential element in the promotion of wellbeing, social, and economic integration for groups who have been consistently sidelined. Social and structural contexts and provisions for basic life needs are essential for learning and continued development in addition to necessary job skills training. Matters of equity and inclusion are critical for effective and meaningful adult learning. The policy "holes," however, reveal that the infrastructure and technology, teaching and learning practices, transitions between sectors/institutions, and equity and inclusion measures tend to be overlooked in favor of an employment emphasis.

Adults' lives, social, and economic contexts must all be taken into consideration (Alfred, 2002; Cincinnato et al., 2016), but the policy facets that would address these in federal legislation seem to be the least developed. The patterns that emerged from the policy analyses reveal that U.S. policies are underdeveloped precisely in areas that influence learner participation: infrastructure and technology to support access, participation, and digital literacy; curriculum and teaching practices that are effective for marginalized adult populations; basic social needs and wellbeing; and matters of equity and inclusion as related to education and jobs training. The findings also highlight the need for further development in the area of culturally congruent educational programming. 
The year 2020 laid bare many areas of acute need: digital literacy and digital inclusion; the need for educators' professional development in instructional technologies, hyflex delivery, and media-driven learning activities; improved general AWE reform leading to meaningful learning experiences paired with dignified work and sustainable wages; and finally, a need for stronger social policies related to matters of diversity, social inclusion, digital equity, equity in education, and educational, social, and income inequality. When our current social and structural conditions are taken into consideration together with the "holes" in AWE policy, we can identify avenues for action.

\section{Possible Areas for Policy Advocacy}

\section{Reach and Access}

WIOA's content contains sprinklings of policy framing language and mandates regarding instructional technology and the integration of digital literacy into curricula, but 2020 has stressed the need to address digital equity and inclusion as a fundamental basis for human thriving in the $21^{\text {st }}$ century (DigitalUS Coalition, 2020). The pandemic has revealed the heightened need for improved infrastructure and Internet services. We must pursue policies that bolster internet and technology infrastructure, get technologies and applications into learners' hands, and emphasize the need for policies that address matters of digital equity and inclusion.

\section{Professional Development}

The COVID-19 pivot caught many educators off guard and highlighted the increasing demand for flexible instructional delivery. Current experience and newly emerging research will reveal areas of need for professional development and innovations in delivering instruction and training for adult learners.

\section{Learning and Earning}

Adult education research emphasizes the context and conditions necessary to support individual growth and social thriving. AWE policy must emphasize the broadening of choice and options for all and provide adequate learning and community conditions that generate good health, wellbeing, civic and community participation, and the opportunity to live a meaningful and dignified life. The economic and jobs focus is not enough, we will need to better integrate and enhance the social, equity, and inclusion aspects into AWE policies as well.

\section{Economic Justice}

Carnevale et al. (2019) recently released data exposing significant and growing income gaps between White, Black, and Latinx populations in the United States, demonstrating how access to education and workforce training can play an important role in reducing income inequality. The current economic paralysis and increased unemployment have foregrounded the urgent need for dignified jobs and family sustaining employment. The increasing demand for higher levels of literacy, education, training, and skills will also continue to directly impact the livelihood of millions of individuals, which will also require a perceptive response on the part of education and workforce systems. The report presents a united call to action for advocacy and AWE policy changes to promote economic justice.

\section{Imagine Tomorrow: Act Today}

Over the past 20 years, adult literacy statistics suggest little has changed, and in some respects, the divides are widening (COABE, 2019). The 2014 WIOA policies and mandates improved interoperability and formalized several aspects of the AWE system. However, WIOA continues 
to promote $20^{\text {th }}$ century thinking in a no-longernew $21^{\text {st }}$ century. What seems to be lacking are energizing conversations about innovative policies and new possibilities for empowering and inclusive practice. Together, we need to return to the drawing board and re-imagine how AWE policy can contribute to solutions to address these acute and evolving needs.

The year 2020 has called us to reflect on our role in the evolving narrative of adult education. The AWE policy gaps demonstrate policy development is a viable and necessary path for contributing to and bringing about necessary socio-structural changes. Our field's literature, research, and practice contain a broad collection of philosophies, expertise, reflective praxis, and lived experience that can and must be brought to bear in this historical moment. We must leverage this knowledge and know-how and apply it to AWE policy.

The stakes are too high; we must vigorously pursue new and innovative funding, policy, and programming avenues at all levels. As a field, we must intentionally engage in serious knowledge, resource, and policy mobilization. We must motivate champions and power players who can "go to the matts" at the municipal, state, and federal levels. Locally, we need to continue engaging with workforce boards, organizations, and funders, and ensure AWE policies are informed by and respond to the real, on-theground, and contextualized needs of adult learners. If not, our efforts will amount only to tiny drops in a giant bucket of need.

We will need to collectively re-vision what adult and workforce education can look like post-2020: an AWE system that has more engines than it has brakes. Even supposing, an engine with no fuel is inoperable. I echo Vanek et al.'s call for unified action in their spring 2020 viewpoint article, where they illustrated examples of how educators can come together to support immigrants' and refugees' learning and life transition needs. We are all learning and transitioning and must continue to actively pursue creative partnerships. The theme of partnership is strong throughout WIOA; building partnerships is how many AWE providers have survived the last 20 years, and partnerships are how we will persist post-2020. 


\section{References}

Alamprese, J. (2016). Building career pathways systems for education, training, and employment. Manhattan Strategy Group.

Alfred, M. V. (2002). The promise of sociocultural theory in democratizing adult education. New Directions for Adult and Continuing Education, 96, 3-13.

Alfred, M. C. (2020). Leadership of adult education and family literacy organizations in an era of diminishing resources [Unpublished dissertation]. Texas A\&M University.

Anderson, T., Eyster, L., Lerman, R. I., Conway, M., Jain, R., \& Montes, M. (2016). Implementation of accelerating opportunity: Final implementation findings with lessons from the field. Urban Institute. https://www.urban.org/sites/default/files/alfresco/ publication-pdfs/2000791-Implementation-ofAccelerating-Opportunity-Final-ImplementationFindings-with-Lessons-from-the-Field.pdf

Belzer, A. (2017). Turning points: Recent trends in adult basic literacy, numeracy, and language education. New Directions for Adult \& Continuing Education, 155, 5-9.

Belzer, A., \& Pickard, A. (2015). From heroic victims to competent comrades: Views of adult literacy learners in the research literature. Adult Education Quarterly, 65(3), 250-266. https://doi. org/10.1177/0741713615580015

Bok, D. (2013). Higher education in America. Princeton University Press.

Brown, E., \& Holcomb, P. (2018). An institutional analysis of American Job Centers: Key institutional features of American Job Centers. U.S. Department of Labor. https://wdr.doleta.gov/research/FullText_Documents/ ETAOP_2018-03_KeyFeatures_AJCs_508_ Compliant.pdf
Carnevale, A. P., Strohl, J., Gulish, A., van der Werf, M., \& Campbell, K. P. (2019). The unequal race for good jobs: How Whites made outsized gains in education and good jobs compared to Blacks and Latinos. Georgetown University Center on Education and the Workforce. https://1 gyhoq479ufd3yna29x7ubjn-wpengine. netdna-ssl.com/wp-content/uploads/Full_Report-The Unequal_Race_for_Good_Jobs.pdf

Campbell, C. \& Love, I. (2016) State-federal partnerships in postsecondary education. Leveraging community colleges in the Workforce Innovation and Opportunity Act: A blueprint for state policymakers. Education Commission of the States. https://www.ecs.org/ leveraging-community-colleges-in-the-workforceinnovation-and-opportunity-act-a-blueprint-for-statepolicymakers/

Cincinnato, S., De Wever, B., Van Keer, H., \& Valcke, M. (2016). The influence of social background on participation in adult education: Applying the cultural capital framework. Adult Education Quarterly, 66(2), 143-168. https://doi.org/10.1177/0741713615626714

Coalition on Adult Basic Education (COABE) (2019). Educate and Elevate. https://coabe.org/strategicinitiatives/\#educate-and-elevate

DigitalUS Coalition. (2020, May). Building a digitally resilient workforce: Creating on-ramps for opportunity, Annual Report. https://digitalus.org/wp-content/ uploads/2020/05/DigitalUS-PreviewReportMay5-2020.pdf

Eyster, L., \& Nightingale, D. S. (2017). Workforce development and low-income adults and youth: The future under the Workforce Innovation and Opportunity Act of 2014. Urban Institute. https://www.urban.org/ research/publication/workforce-development-and-lowincome-adults-and-youth/view/full_report

Finnegan, F. (2016). The future is unwritten: Democratic adult education against and beyond neoliberalism. https://files.eric.ed.gov/fulltext/EJ1117510.pdf 
Jacobson, E. (2017). The Workforce Investment and Opportunity Act: New policy developments and persistent issues. New Directions for Adult \& Continuing Education, 155, 19-27. https://doi. org/10.1002/ace.20237

Ladinsky, J. (2017). From WIA to WIOA: Lessons for the implementation of the Workforce Innovation and Opportunities Act. Journal of Rehabilitation Administration, 39(2), 107-117.

McConnell, S., Fortson, K., Rotz, D., Schochet, P., Burkander, P., Rosenberg, L., Mastri, A. \& D’Amico, R. (2016). Providing public workforce services to job seekers: 15-month findings on the WIA adult and dislocated worker programs. Mathematica Policy Research.

McDonnell, R. P., \& Soricone, L. (2018). Integrated Career Pathways: Lessons from accelerating opportunity. Journal of Research \& Practice for Adult Literacy, Secondary \& Basic Education, 52-62.

McHugh, M., \& Doxsee, C. (2018). English plus integration: Shifting the instructional paradigm for immigrant adult learners to support integration success. Policy Brief. Migration Policy Institute. https://www.migrationpolicy.org/research/english-plusintegration-instructional-paradigm-immigrant-adultlearners

Milana, M., \& McBain, L. (2015). Adult and continuing education policy in the USA. In M. Milana \& T. Nesbit (Eds.), Global perspectives on adult and continuing education policy (pp. 44-59). Palgrave.

Mortrude, J. (2018). Career pathways: Failure to focus on economic impacts diminishes adult education. $C O A B E$ Journal, 2018, 109-115. https://static1.squarespace. com/static/55a 158b4e4b0796a90f7c371 /t/5b5a26a0758d46f380a4f612/1532634789204/ The+Resource+for+Adult+Education+Career + Pathways + Special + Edition.pdf

Patterson, M. B. (2018). The forgotten 90\%: Adult nonparticipation in education. Adult Education Quarterly, 68, 41-62. https://doi. org/10.1177/0741713617731810
Prins, E., \& Clymer, C. (2018). Career Pathways in Chicago, Houston, and Miami: Key features and support services among adult education providers. Journal of Research \& Practice for Adult Literacy, Secondary \& Basic Education, 28-51.

Pickard, A. (2016). WIOA: Implications for low-scoring adult learners. Journal of Research and Practice for Adult Literacy, Secondary, and Basic Education, 5(2), $50-55$.

Pickard, A. (2019). Barriers to access in public adult literacy education. Educational Policy. https://doi. org/10.1177/0895904819843602

Rasmussen, A. (in press). Accessibility of general adult education. An analysis of the restructuring of adult education governance in Denmark. Adult Education Quarterly.

Rose, A. D. (1999). Adult education as a means, but not an end: United States policy in the twentieth century. Adult Learning, 10(3), 4-5.

Roumell, E. E. A. \& Salajan, F. D. (2014). A comparative analysis of e-learning policy formulation in the European Union and the United States: Discursive convergence and divergence. Comparative Education Review, 58(1), 135-165.

Roumell, E. A., Salajan, F. D., \& Todoran, C. (2019). An analysis and illustration of the U.S. adult and workforce education policy domain. Adult Education Quarterly, 69(4), 295-314. https://doi. org/10.1177/0741713619856097

Roumell, E. A., Salajan, F. D., \& Todoran, C. (2020). A survey of U.S. education policy regarding the education of adults. Educational Policy, 34(5), 785-815. https:// doi.org/10.1177/0895904818802416

Sandlin, J. (2005). Andragogy and its discontents: An analysis of andragogy from three critical perspectives. PAACE Journal of Lifelong Learning, 14, 25-42.

Schochet, P. Z., Burghardt, J., \& McConnell, S. (2008). Does Job Corps work? Impact findings from the National Job Corps Study. American Economic Review, 98(5), 1864-1866. 
U. S. Department of Education. (2014). Program for the International Assessment of Adult Competencies (PIAAC) 2012: U.S. Main Study Technical Report. National Center for Education Statistics. https://nces. ed.gov/pubs2014/2014047.pdf

U.S. Department of Labor. (2012). Joint letter from https://careerpathways.workforcegps.org/ resources/2016/04/27/12/12/Career_Pathways_Joint_ Letter_2016

U.S. Departments of Labor, Commerce, Education, and Health and Human Services. (2014). What works in job training: A synthesis of the evidence. https://www.dol. gov/asp/evaluation/jdt/jdt.pdf

U.S. Department of Labor, Employment and Training Administration. (2016). Career pathways joint letter 2016 from https://careerpathways.workforcegps.org/ resources/2016/04/27/12/12/Career_Pathways_Joint_ Letter_2016
Uvin, J. E. (2018). Are we on the brink of something big? Reflections on the current and future state of Career Pathways policy and practice. Journal of Research \& Practice for Adult Literacy, Secondary \& Basic Education, 97-108.

Vanek, J., Wrigley, H. S., Jacobson, E., \& Isserlis, J. (2020, Spring). All together now: Supporting immigrants and refugees through collaboration. Adult Literacy Education: The International Journal of Literacy. Language, and Numeracy, 2(1), p. 41-47.

Wilson, A. L. (2009). Adult education in the United States as a subject of policy and politics. Bildung und Erziehung, 62(4), 451-461.

Workforce Innovation and Opportunity Act, Pub. L. No. 113-128, 128 Stat. 1425 (2014). https://www.govinfo. gov/content/pkg/PLAW-113publ128/pdf/PLAW113publ128.pdf 